Eur. J. Clin. Chom. Clin. Biochem.

Vol. 31, 1993, pp. 689-694

(C) 1993 Walter de Gruyter \& Co. Berlin - New York

\title{
Comparison of Cytokeratin Fragment 19 (CYFRA 21-1), Tissue Polypeptide Antigen (TPA) and Tissue Polypeptide Specific Antigen (TPS) as Tumour Markers in Lung Cancer
}

\author{
By Petra Stieber ${ }^{1}$, H. Dienemann ${ }^{2}$, Ute Hasholzner ${ }^{1}$, C. Müller ${ }^{2}$, Susanne Poley ${ }^{1}$, Karin Hofmann ${ }^{1}$ and \\ A. Fatch-Moghadam ${ }^{1}$ \\ 1 Institut für Klinische Chemie, Klinikum Großhadern \\ ${ }^{2}$ Chirurgische Klinik und Poliklinik. Klinikum Großhadern \\ Ludwig-Maximilians-Universität München, Germany
}

(Reccived April 26/June 24, 1993)

Summary: Recently CYFRA 21-1, a new tumour marker measuring a fragment of cytokeratin 19, was introduced $(1,2)$ and proved to be suitable for the follow-up care and monitoring of the therapy of non-small cell lung carcinomas, especially squamous cell carcinomas of the lung $(3,4)$. Besides CYFRA 21-1, there are two other tumour markers available, called tissue polypeptide antigen (TPA) and tissue polypeptide specific antigen (TPS), which also measure different cytokeratins in serum. In a retrospective study we investigated the clinical significance of these 3 cytokeratin markers in lung cancer compared with carcinoembryonic antigen (CEA), squamous cell carcinoma antigen (SCC) and neuron-specific enolase (NSE). We investigated the sera of 50 healthy persons, 273 patients with various benign diseases and 218 patients with histologically proven lung cancer. In a first step the specificity versus benign diseases of the lung was established for all the markers, and was fixed at $95 \%$. Then the single and combined sensitivities were calculated. CYFRA 21-1 proved to possess the highest sensitivity in lung cancer in general $(61 \%)$, in non-small cell lung carcinomas $(64 \%)$, in squamous cell carcinomas (79\%), in adenocarcinomas (54\%) and in large cell carcinomas $(65 \%)$. In small cell lung carcinomas, neuron-specific enolase proved again to be the marker of first choice (55\%). Combined determinations proved clearly increased sensitivity only for large cell carcinomas (CYFRA 21-1 + TPA: 77\%) and for small cell lung carcinomas (CYFRA 21-1 + NSE: 62\%). From our investigations it was evident that TPA detects at least partly the same substance as CYFRA 21-1 (the sensitivities compared with the markers TPS, CEA, SCC and NSE were rather high, but not as high as for CYFRA 21-1), whereas the TPS assay measures a completely different clinical chemical analyte (lowest number of true positive test results over the whole investigation). These findings correspond cleary to the very recent results of the comparison of CYFRA 21-1, TPA and TPS by immunoblotting (5).

\section{Introduction}

In many industrialized countries, lung cancer is the most common cancer in men and is climbing quickly toward the same incidence in women. Clinical chemical methods for the support of adequate follow up care and the control of efficiency of therapy are available only for small cell lung carcinomas, and they consist of the determination of neuron specific enolase $(6,7)$.
Recently a new tumour marker, called CYFRA 21-1, was described for the detection of cytokeratin 19fragments in serum $(1,2)$. Cytokeratins and other intermediate filaments of the cell like vimentin and desmin have become well known since the development of monoclonal antibodies in histopathology for the differentiation and classification of physiological and pathological tissues $(8,9)$. The expression of a single cytokeratin or a combination of certain cyto- 
keratins is typical for defined tissues, for example cytokeratin 7 and 8 in the epithelium of the trachea and urothelium. In contrast to cytokeratins themselves. fragments of intermediate filaments are soluble in serum and can therefore be detected and measured with the aid of monoclonal antibodies. Since cytokeratin 19 is particulary abundant in carcinoma of the lung $(10,11)$, the assay CYFRA 21-1, combining two monoclonal antibodies directed specifically against this cytokeratin, was developed $(1,2)$.

According to our own investigations, $(3,4)$ and the results of a European multicentre study, CYFRA 21-1 shows a good specificity-sentitivity-profile in lung cancer and is suitable for diagnosis, control of therapy efficiency and follow up care of patients with nonsmall cell lung carcinoma, especially squamous cell carcinomas of the lung. TPA and TPS are two other tumour markers, which represent different cytokeratins in serum. In the present investigation we compared the presence of CYFRA 21-1, TPA and TPS in various benign diseases and their significance in lung cancer.

\section{Patients}

Two reference groups were investigated: 50 persons who were normal according to clinical examination, and showed no abnormal serum values of clinical chemical analytes; and 273 patients with various benign disorders including 58 patients with benign diseases of the lung (tuberculosis, sarcoidosis, aspergillosis, pneumonia, chronic obstruction, hamartoma), 46 with benign diseases of the gastrointestinal tract (liver cirrhosis, hepatitis, pancreatitis, primary biliary cirrhosis, colitis ulcerosa, Crohn's disease), 30 women with benign disorders of the breast (mastopathia stage I, II, III, fibroadenoma, galactorrhoe), 73 patients with benign urological diseases (stones, urinary infections), 31 patients with chronic or acute renal failure and 30 patients with benign gynaecological diseases. As tumour patients we investigated the sera of 218 patients with histologically proven lung cancer (62 small cell, 67 adeno, 66 squamous cell, 17 large cell and 6 undifferenciated); all of them were collected at an active stage of disease (primary diagnosis or recurrent disease). As this study was done retrospectively, the sera were stored at $-70^{\circ} \mathrm{C}$ in our serum bank.

\section{Methods}

The CYFRA 21-1 concentrations were determined by using the two-step-sandwich Enzymun ${ }^{(1)}$-assay (Boehringer Mannheim, Germany) on the automated test system ES600. TPA values were determined with the IRMA of Sangtec Medicals (Sweden) and TPS values with the IRMA of Beki Diagnostics (Sweden). For the CEA and SCC values we used the enzyme immunoassays on the IMx (automated test system, Abbott, USA) and for the neuron-specific enolase determinations the radioimmunoassay from Pharmacia (Sweden).

\section{Results}

\section{Correlation of CYFRA 21-1, TPA and TPS}

The coefficients of correlation for all sera investigated were $r=0.77$ for CYFRA 21-1 \& TPA, $r=0.41$ for CYFRA 21-1 \& TPS and $r=0.65$ for TPA \& TPS; for the reference groups we obtained $\mathrm{r}=0.6$ for $\mathrm{CY}$ FRA 21-1 \& TPA, $r=0.36$ for CYFRA 21-1 \& TPS, and $r=0.76$ for TPA \& TPS. In squamous cell carcinomas of the lung the coefficients of correlation of CYFRA 21-1 \& TPA was $r=0.83$, of CYFRA 21-1 $\&$ TPS $\mathrm{r}=0.36$, and of TPA \& TPS $\mathrm{r}=0.49$.

\section{Diagnostic specificity}

In order to compare our results for the different tumour markers under the same conditions we followed the recommendations of the "Hamburger group for the standardization of tumour markers" (12) and fixed the cut off values for each reference group at a specificity of $95 \%$. This basic postulation resulted in many different cut off-values (tab. 1). In $95 \%$ of the normal healthy controls, CYFRA 21-1values were then below $1.8 \mu \mathrm{g} / \mathrm{l}$, TPA-values were below $133 \mathrm{U} / 1$ and TPS-values were below $97 \mathrm{U} / \mathrm{l}$. In patients with benign diseases of the lung the cut off changed to a small extent for CYFRA 21-1 $(2.1 \mu \mathrm{g} / \mathrm{l})$ and for TPA (131 U/l), and to a greater extent for TPS $(237 \mathrm{U} / 1)$.

Higher cut off values were necessary in benign diseases of the gastrointestinal tract: CYFRA 21-1: $5.2 \mu \mathrm{g} / \mathrm{l}$, TPA: 713 U/l; TPS: $2021 \mathrm{U} / \mathrm{l}$.

Tab. 1. Cut off values of cytokeratin fragment 19 (CYFRA 21-1), tissue polypeptide antigen (TPA) and tissue polypeptide specific antigen (TPS) at a specificity of $95 \%$ versus healthy persons and various groups of patients with benign diseases.

\begin{tabular}{|c|c|c|c|c|c|c|c|}
\hline \multirow[t]{2}{*}{ Patients } & \multirow{2}{*}{$\begin{array}{l}\text { Healthy } \\
\mathrm{n}=50\end{array}$} & \multicolumn{6}{|c|}{ Benign diseases } \\
\hline & & $\begin{array}{l}\text { Pulmonal } \\
\mathrm{n}=58\end{array}$ & $\begin{array}{l}\text { Gastro- } \\
\text { intestinal } \\
n=46\end{array}$ & $\begin{array}{l}\text { Gynaeco- } \\
\text { logical } \\
n=30\end{array}$ & $\begin{array}{l}\text { Urological } \\
n=73\end{array}$ & $\begin{array}{l}\text { Renal } \\
\text { failure } \\
n=31\end{array}$ & $\begin{array}{l}\text { Breast } \\
\mathrm{n}=35\end{array}$ \\
\hline $\begin{array}{l}\text { CYFRA } 21-1 \mu \mathrm{g} / 1 \\
\text { TPA U/1 } \\
\text { TPS U/1 }\end{array}$ & $\begin{array}{c}1.8 \\
133 \\
97\end{array}$ & $\begin{array}{l}2.1 \\
131 \\
237\end{array}$ & $\begin{array}{c}5.2 \\
713 \\
2021\end{array}$ & $\begin{array}{l}3.9 \\
195 \\
214\end{array}$ & $\begin{array}{l}2.6 \\
165 \\
144\end{array}$ & $\begin{array}{l}7.2 \\
322 \\
404\end{array}$ & $\begin{array}{l}1.3 \\
243 \\
226\end{array}$ \\
\hline
\end{tabular}


In $95 \%$ of benign gynaecological disorders, tumour marker concentrations were below the following cut off values: CYFRA 21-1: $3.9 \mu \mathrm{g} / 1$, TPA: $195 \mathrm{U} / 1$, TPS: $214 \mathrm{U} / \mathrm{l}$.

Women with masthopathia and other benign diseases of the mammary gland proved to have rather low CYFRA 21-1-concentrations (95\% cut off $1.3 \mu \mathrm{g} / \mathrm{l}$ ); for TPA we obtained a cut off of $243 \mathrm{U} / 1$ and for TPS $226 \mathrm{U} / 1$.

In benign urological disorders without remarkable renal failure $95 \%$ of the patients showed CYFRA 21 1-values below $2.6 \mu \mathrm{g} / \mathrm{l}$, TPA-values below $165 \mathrm{U} / \mathrm{l}$ and TPS-values below $144 \mathrm{U} / \mathrm{l}$.

In patients with acute or chronic renal failure (with or without haemodialysis) higher cut off-values had to be taken to obtain a 95\% specificity: CYFRA 21 1: $7.2 \mu \mathrm{g} / 1, \mathrm{TPA}: 243 \mathrm{U} / 1$ and TPS: $404 \mathrm{U} / 1$.

\section{Diagnostic sensitivity}

To examine the clinical potential of CYFRA 21-1, TPA, TPS, CEA, SCC and NSE we compared the true positive test results based on a $95 \%$ specificity versus the clinically relevant reference group, in this case benign diseases of the lung. In these benign pulmonary disorders the cut off (at a specificity of 95\%) value of CYFRA $21-1$ was $2.1 \mu \mathrm{g} / \mathrm{l}$, of TPA 131 $\mathrm{U} / \mathrm{l}$, of TPS $237 \mathrm{U} / \mathrm{l}$, of CEA $7.4 \mu \mathrm{g} / \mathrm{l}$, of SCC 2.4 $\mu \mathrm{g} / 1$ and of NSE $18 \mu \mathrm{g} / \mathrm{l}$. The distribution of the CYFRA 21-1, TPA and TPS concentrations at the above mentioned cut off values is shown in figure 1.

Independent of the histological type and with $61 \%$ true positive test results CYFRA 21-1 showed a clearly higher sensitivity in lung cancer than the other markers: TPA (51\%), TPS (22\%), CEA (29\%), SCC $(18 \%)$ and NSE (19\%) (tab. 2). This high sensitivity could not be markedly increased by any of the different forms of combinations shown in table 3.

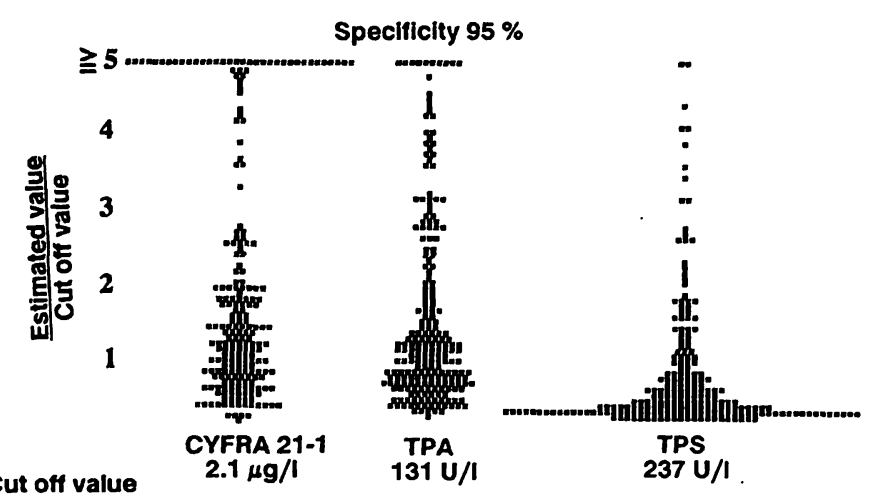

Fig. 1. Distribution of the values of cytokeratin fragment 19 (CYFRA 21-1), tissue polypeptide antigen (TPA) and tissue polypeptide specific antigen (TPS) in lung cancer regardless of the histological type.

The scale is equalized by dividing the values by the cut off at $95 \%$ specificity versus benign lung diseases.

If the different carcinomas of the lung are classified according to their histological type (tab. 2), CYFRA $21-1$, with $64 \%$ true positive test results, possessed the highest sensitivity for all non-small cell lung carcinomas, followed by TPA (50\%), CEA (33\%), SCC $(19 \%)$ and TPS (17\%). Again, no combination of tests (tab. 3) significantly increased the number of true positive test results.

In agreement with our pilot study (9), CYFRA 21-1 showed high diagnostic sensitivity $(79 \%)$ for squamous cell carcinomas of the lung (tab. 2). Corresponding values for other tests were: TPA $(62 \%)$, SCC $(38 \%)$, TPS $(18 \%)$ and CEA $(25 \%)$. This good profile of specificity and sensitivity of CYFRA $21-1$ is illustred by the receiver operating characteristic curves in figure 2. The number of true positive test results of the different tumour marker combinations was inferior to those achieved by the single determination of CYFRA 21-1.

Tab. 2. Sensitivity (\%) of cytokeratin fragment 19 (CYFRA 21-1), tissue polypeptide antigen (TPA), tissue polypeptide specific antigen (TPS), carcinoembryonic antigen (CEA), squamous cell carcinoma antigen (SCC) and neuron specific enolase (NSE) in lung cancer following the histological classification.

The cut off values were fixed at a specificity of $95 \%$ versus benign lung diseases: CYFRA $21-1: 2.1 \mu \mathrm{g} / \mathrm{l} ; \mathrm{TPA}: 131 \mathrm{U} / \mathrm{l}$; TPS: $237 \mathrm{U} / \mathrm{l} ; \mathrm{CEA}: 7.4 \mu \mathrm{g} / \mathrm{l} ; \mathrm{SCC} 2.4 \mu \mathrm{g} / \mathrm{l} ; \mathrm{NSE}: 18 \mu \mathrm{g} / \mathrm{l}$.

\begin{tabular}{|c|c|c|c|c|c|c|}
\hline \multirow[b]{2}{*}{ Marker } & \multicolumn{6}{|c|}{ Lung cancer } \\
\hline & $\begin{array}{l}\text { All } \\
n=218\end{array}$ & $\begin{array}{l}\text { Non-small cell } \\
\mathrm{n}=156\end{array}$ & $\begin{array}{l}\text { Squamous } \\
\mathrm{n}=66\end{array}$ & $\begin{array}{l}\text { Adeno } \\
\mathrm{n}=67\end{array}$ & $\begin{array}{l}\text { Large cell } \\
\mathrm{n}=17\end{array}$ & $\begin{array}{l}\text { Small cell } \\
\mathrm{n}=62\end{array}$ \\
\hline CYFRA 21-1 & 61 & 64 & 79 & 54 & 65 & 52 \\
\hline TPA & 51 & 50 & 62 & 40 & 41 & 52 \\
\hline TPS & 22 & 17 & 18 & 16 & 18 & 32 \\
\hline CEA & 29 & 33 & 25 & 41 & 27 & 18 \\
\hline SCC & 18 & 19 & 38 & 5 & 1 & 6 \\
\hline NSE & 19 & 5 & 5 & 3 & 9 & 55 \\
\hline
\end{tabular}


Tab. 3. Sensitivity of the combinations of cytokeratin fragment 19 (CYFRA 21-1), tissue polypeptide antigen (TPA), tissue polypeptide specific antigen (TPS), carcinoembryonic antigen (CEA), squamous cell carcinoma antigen (SCC) and neuron specific enolase (NSE) in lung cancer at a specificity of $95 \%$ versus benign diseases of the lung. For the calculations both markers combined had to fulfil the specificity of $95 \%$ and at least one of them had to show a true positive test result.

\begin{tabular}{|c|c|c|c|c|c|c|}
\hline \multirow[t]{2}{*}{ Tumour } & \multicolumn{6}{|c|}{ Lung cancer } \\
\hline & $\begin{array}{l}\text { All } \\
n=218\end{array}$ & $\begin{array}{l}\text { Non-small cell } \\
\mathrm{n}=156\end{array}$ & $\begin{array}{l}\text { Squamous } \\
\mathrm{n}=66\end{array}$ & $\begin{array}{l}\text { Adeno } \\
\mathrm{n}=67\end{array}$ & $\begin{array}{l}\text { Large cell } \\
\mathrm{n}=17\end{array}$ & $\begin{array}{l}\text { Small cell } \\
\mathrm{n}=62\end{array}$ \\
\hline CYFRA $21-1$ or TPS & 54 & 58 & 71 & 46 & 53 & 47 \\
\hline CYFRA $21-1$ or TPA & 63 & 67 & 76 & 55 & 77 & 55 \\
\hline CYFRA $21-1$ or CEA & 54 & 58 & 60 & 55 & 52 & 40 \\
\hline CYFRA $21-1$ or SCC & 51 & 55 & 67 & 44 & 44 & 35 \\
\hline CYFRA 21-1 or NSE & 56 & 53 & 60 & 45 & 54 & 62 \\
\hline TPS or TPA & 31 & 29 & 33 & 22 & 35 & 37 \\
\hline TPS or CEA & 39 & 35 & 30 & 38 & 35 & 40 \\
\hline TPS or SCC & 30 & 29 & 40 & 19 & 23 & 34 \\
\hline TPS or NSE & 28 & 19 & 18 & 18 & 23 & 53 \\
\hline TPA or CEA & 56 & 56 & 63 & 53 & 41 & 56 \\
\hline TPA or SCC & 60 & 61 & 76 & 49 & 47 & 56 \\
\hline TPA or NSE & 55 & 51 & 62 & 42 & 47 & 64 \\
\hline
\end{tabular}

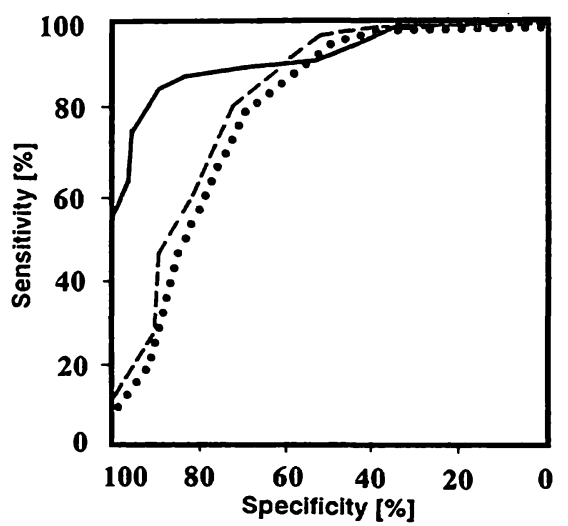

Fig. 2. Receiver operating characteristic curves ROC of cytokeratin fragment 19 (CYFRA 21-1):

tissue polypeptide antigen (TPA):

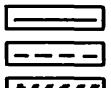

tissue polypeptide specific antigen (TPS):

$\ldots$

Specificity: benign lung diseases $(n=58)$

Sensitivity: squamous cell carcinomas of the lung ( $\mathrm{n}=$ 66)

The more the curves approach the left upper corner, the better is the discrimination between benign and malignant lung diseases.
In adenocarcinomas of the lung (tab. 2) the sensitivity of CYFRA $21-1$ was $54 \%$ (TPA $40 \%$, CEA $41 \%$, TPS $16 \%$ and SCC $5 \%$ ). None of the combinations could improve this diagnostic sensitivity.

CYFRA 21-1 also showed the best specificity-sensitivity profile in large cell carcinomas of the lung, with $65 \%$ true positive test results (TPA $41 \%$, TPS $18 \%$, CEA $27 \%$, SCC 1\%).

In small cell lung carcinomas the diagnostic sensitivity of CYFRA 21-1 was about 52\%, while NSE showed a true positive test result in $55 \%$ of the cases (TPA $52 \%$, TPS $32 \%$, CEA $18 \%$, SCC $6 \%$ ).. This high sensitivity could be slightly increased to $62 \%$ only by combining CYFRA 21-1 with NSE.

For all non-small cell lung carcinomas the sensitivities were also calculated following tumour size and tumour stages (tab. 4). For CYFRA 21-1 we found a clear correlation both with tumour size (T1: 15\%, T4: $55 \%$ ) and tumour stage (stage I: $29 \%$, stage IV: $63 \%$ ). Concerning tumour size there was no correlation for

Tab. 4. Sensitivity of cytokeratin fragment 19 (CYFRA 21-1), tissue polypeptide antigen (TPA), tissue polypeptide specific antigen (TPS), carcinoembryonic antigen (CEA) and squamous cell carcinoma antigen (SCC) in lung cancer, depending on tumour size and tumour stage.

Specificity $95 \%$ versus benign lung diseases.

\begin{tabular}{|c|c|c|c|c|c|c|c|c|c|c|}
\hline \multirow[t]{2}{*}{ Tumour } & \multirow{2}{*}{$\begin{array}{l}\text { All } \\
\mathrm{n}=156\end{array}$} & \multicolumn{4}{|c|}{ Tumour size } & \multicolumn{5}{|c|}{ Tumour stages } \\
\hline & & $\begin{array}{l}\mathrm{T}_{1} \\
\mathrm{n}=27\end{array}$ & $\begin{array}{l}\mathrm{T}_{2} \\
\mathrm{n}=67\end{array}$ & $\begin{array}{l}\mathrm{T}_{3} \\
\mathrm{n}=21\end{array}$ & $\begin{array}{l}T_{4} \\
N\end{array}=11$ & $\begin{array}{l}I \\
n\end{array}=48$ & $\begin{array}{l}\mathrm{II} \\
\mathrm{n}=22\end{array}$ & $\begin{array}{l}\text { IIIIa } \\
n=26\end{array}$ & $\begin{array}{l}\text { UIb } \\
n=11\end{array}$ & $\begin{array}{l}\text { IV } \\
n=19\end{array}$ \\
\hline $\begin{array}{l}\text { CYFRA } 21-1 \\
\text { TPA } \\
\text { TPS } \\
\text { CEA } \\
\text { SCC }\end{array}$ & $\begin{array}{l}64 \\
50 \\
17 \\
33 \\
19\end{array}$ & $\begin{array}{r}30 \\
4 \\
4 \\
20 \\
8\end{array}$ & $\begin{array}{l}67 \\
53 \\
22 \\
25 \\
19\end{array}$ & $\begin{array}{l}76 \\
61 \\
10 \\
61 \\
33\end{array}$ & $\begin{array}{r}55 \\
0 \\
-\quad 0 \\
54 \\
36\end{array}$ & $\begin{array}{l}48 \\
23 \\
10 \\
18 \\
21\end{array}$ & $\begin{array}{l}72 \\
68 \\
27 \\
24 \\
19\end{array}$ & $\begin{array}{l}61 \\
54 \\
19 \\
58 \\
21\end{array}$ & $\begin{array}{r}50 \\
25 \\
0 \\
0 \\
25\end{array}$ & $\begin{array}{l}84 \\
74 \\
21 \\
58 \\
21\end{array}$ \\
\hline
\end{tabular}


TPA (T1: 4\%, T4: 0\%) and also none for TPS (T1: $4 \%$, T4: $0 \%$ ). CEA proved to have a good correlation (T1: $11 \%, \mathrm{~T} 4: 54 \%$ ) and to a lower extent also SCC (T1: $7 \%, \mathrm{~T} 4: 36 \%$ ).

TPA and TPS again proved to be independent of the extent of disease, as their sensitivities were almost the same for stage II (TPA: 55\%, TPS: $23 \%$ ) and stage IV (TPA: $46 \%$, TPS 18\%). The CEA-values were clearly dependent on tumour stages (stage I: $15 \%$, stage IV: $57 \%$ ), whereas the number of true positive SCC-results showed no correlation (stage I: $19 \%$, stage IV: $22 \%$ ).

\section{Discussion}

Like most the other tumour markers, cytokeratins are not organ specific and therefore can be expressed in all human tissues. We compared the expression of the "cytokeratin markers" CYFRA 21-1, TPA and TPS in various benign diseases before addressing the main question of this investigation concerning their clinical significance in lung cancer. Because we fixed the different specificities at a level of $95 \%$, we obtained, for most of the different reference groups investigated, significantly higher cut off values than those normally used in routine laboratories (tab. 1). This fact of course results in fewer true positive test results and therefore in a lower diagnostic sensitivity. Compared with the marker values obtained for the healthy control group, the cut off values necessary for a specificity of $95 \%$ in benign diseases of the lung (tab. 1) did not clearly change for CYFRA 21-1 $(2.1 \mu \mathrm{g} / \mathrm{l})$ and TPA (131 U/l), but were different for TPS (237 U/l). In benign gynaecological disorders the cut off values were almost the double for all 3 markers as compared with the healthy persons. In patients with mastopathia the CYFRA 21-1 values were very low (cut off: 1.3 $\mu \mathrm{g} / \mathrm{l}$ ), whereas TPA and TPS were increased (TPA: 243 U/1, TPS: 226 U/1). Benign urological diseases only slightly influenced all markers, whereas renal failure was combined with a clear increase of CYFRA 21-1 (cut off: $7.2 \mu \mathrm{g} / \mathrm{l}$ ), TPA (cut off: $243 \mathrm{U} / \mathrm{l}$ ) and TPS (cut off: $404 \mathrm{U} / 1$ ), probably due to the fact that cytokeratin fragments are eliminated by the renal pathway and therefore accumulate in renal failure. The highest influence, especially on the TPA and TPS concentrations, was caused by benign disorders of the gastrointestinal tract: TPA (cut off: $713 \mathrm{U} / \mathrm{l}$ ) and moreover TPS (cut off: $2021 \mathrm{U} / \mathrm{l}$ ); CYFRA 21-1 showed slightly elevated levels (cut off: $5.2 \mu \mathrm{g} / \mathrm{l}$ ).

In lung cancer, NSE, with a sensitivity of $55 \%$, was confirmed as the marker of first choice for small cell lung carcinomas (CYFRA 21-1: 52\%, TPA: 52\%, TPS: $32 \%$, CEA: $18 \%$, SCC: $6 \%$ ).

In non-small cell lung carcinomas, CYFRA 21-1 discriminated with $64 \%$ sensitivity at a $95 \%$ specificity better between benign diseases of the lung and lung carcinomas than TPA (50\%), TPS (17\%), CEA (33\%) and SCC (19\%). Moreover, as demonstrated in table 4 , the sensitivity of CYFRA 21-1 correlates clearly with tumour size and tumour stage.

In adenocarcinomas of the lung, CYFRA 21-1, with $54 \%$ true positive test results, showed the highest sensitivity (also compared with the combined determinations), followed by TPA ( $40 \%)$ and CEA ( $41 \%)$. TPS (16\%) and SCC (5\%) showed a very small number of true positive test results.

In large cell lung carcinomas, CYFRA 21-1 revealed a sensitivity of $65 \%$ (TPA: $41 \%$, CEA: $27 \%$, TPS: $18 \%$ ). In this case a combination of CYFRA 21-1 and TPA increased sensitivity to $77 \%$. In squamous cell carcinomas of the lung, the benefit of CYFRA 21-1 versus the other markers became evident with $79 \%$ true positive test results (TPA: $62 \%$, CEA: $25 \%$, SCC: $38 \%$, TPS: $18 \%$ ). None of the possible combination could improve this good result (tab. 5).

Independent of the histological type, CYFRA 21-1 emerged as a type of "pan-marker" for lung cancer because of its high overall sensitivity of $61 \%$ in lung cancer (TPA: $51 \%$, CEA: $28 \%$, TPS: $22 \%$, SCC: $18 \%$, NSE: $19 \%$ ). From our investigations it is evident that TPA detects at least partly the same substance as CYFRA 21-1 (the sensitivities compared with the markers TPS, CEA, SCC and NSE were rather high, but not as high as for CYFRA 21-1) whereas TPS represents a completely different clinical chemical analyte (lowest number of true positive test results over the whole investigation). These findings correspond cleary to the very recent results of the comparison of the antibodies used in the CYFRA 211, TPA and TPS assay by immunoblotting. These investigations, presented by Bodenmüller et al. at a recent symposium on cytokeratins (5), show that TPA detects mainly cytokeratin 8 and 19 and to a very small degree cytokeratin 18. Therefore TPA gives the highest number of true positive test results after CYFRA 21-1 (which does not detect cytokeratin 8 and 18 , but only 19). TPS detects mainly cytokeratin 18 and to a small extent 8 and 19. This explains the negligible sensitivities of TPS in lung cancer.

In conclusion, CYFRA 21-1 is superior to the other cytokeratin markers, TPA and TPS, as a marker of lung cancer. 


\section{References}

1. Bodenmüller, H., Banauch, D., Ofenloch, B., Jaworek, D. \& Dessauer, A. (1992) Technical evaluation of a new automated tumour marker assay: the Enzymun-Test CYFRA 21-1. In: Tumor Assciated Antigens, Oncogenes, Receptors, Cytokines in Tumour Diagnosis and Therapy at the Beginning of the 90th (Klapdor, R., ed.) Zuckschwerdt Verlag. pp. $137-138$.

2. Bodenmüller, H., Banauch, D., Ofenloch-Hänle, B., Jaworek, D. \& Dessauer, A. (1992) Technical and clinical evaluation of a new assay for NSCLC, the Enzymun-Test CYFRA 21-1. Proc. Am. Ass. Cancer Res. 33, 203.

3. Stieber, P., Hasholzner, U., Bodenmüller, H., Nagel, D., Sunder-Plassmann, L., Dienemann, H., Meier, W. \& FatehMoghadam, A. (1993) CYFRA 21-1: A new tumour marker in lung cancer. Cancer, in press.

4. Stieber, P., Hasholzner, U. \& Fateh-Moghadam, A. (1992) CYFRA 21-1: Ein neuer Tumormarker für nicht kleinzellige (NSCLC) Bronchialkarzinome. Klin. Wochenschr. 69 (Suppl XXIII), 76.

5. Bodenmüller, H. (1993) Symposium "Cytokeratins and tissue polypeptide antigen" $18^{\text {th }}-19^{\text {th }}$ March 1993 , Istituto nazionale per lo studio e la cura dei tumori, Milano. Publication of the presentations is in preparation in the "International Journal of Biological Markers".

6. Akoun, G. M., Scarna, H. M., Milleron, B. J., Benichou, M. P. \& Herman, D. P. (1985) Serum neuron-specific enolase. A marker for disease extent and response for therapy for small cell lung cancer. Chest $87,39$.
7. Ebert, W., Hug, G., Stabrey, A. \& Bülzebruck, H. (1990) Neuronspezifische Enolase (NSE) als Marker für das kleinzellige Bronchialkarzinom. Tumordiagn. Ther. 11, 60-67.

8. Debus, E., Moll, R., Franke, W. W., Weber, K. \& Osborn, M. (1984) Immunohistochemical distinction of human carcinomas by cytokeratin typing with monoclonal antibodies. Am. J. Pathol. 114, $121-130$.

9. Sundström, B. E., Natrath, W. B. J. \& Stigbrand, T. (1989) Diversity in immunoreactivity of tumour derived cytokeratin monoclonal antibodies. J. Histochem. Cytochem. 37, $1848-1854$.

10. Broers, J. L., Rot, M. K., Oostendorp, T., Huysmans, A.. Wagenaar, S. S., Wiersma-van-Tilburg, A. J., Vooijs, G. P. \& Ramaekers, F. C. (1987) Immunohistochemical detection of human lung cancer heterogeneity using antibodies to epithelial, neuronal and neuroendocrine antigens. Cancer Res. 47, 3225-3234.

11. Broers, J. L., Ramaekers, F.C., Rot, M. K., Oostendorp, T., Huysmans, A., van Muijen, G. N., Wagenaar, S. S. \& Vooijs, G. P. (1988) Cytokeratins in different types of human lung cancer as monitored by chain-specific monoclonal antibodies. Cancer Res. 48, $3221-3229$.

12. Arbeitsgruppe Qualitätskontrolle und Standardisierung von Tumormarkertests im Rahmen der Hamburger Symposien über Tumormarker (1992) Tumordiagn. Ther. 5, XIX - XXII.

Dr. med. Petra Stieber

Institut für Klinische Chemie

Klinikum Großhadern

Marchioninistraße 15

D-81366 München

Germany 